\title{
Design and Comparative Study of Induction and Synchronous Reluctance Motors
}

\author{
Loubna Boudjelida $^{1}$, Redjem Rebbah ${ }^{1}$ and Mohamed Yazid Kaikaa ${ }^{1}$ \\ ${ }^{1}$ Department of Electrotechnique, University of Frère Mentouri Constantine1, Constantine, Algeria
}

\begin{abstract}
This paper proposes a comparison study between induction motor (IM) and synchronous reluctance motor (SynRM), the two machines configuration includes an identical stator but a different rotor structure, the analysis were performed under $2 \mathrm{D}$ model, using finite-elements method in oreder to compare the behavior of both machines in terms of effeciency and electromagnetic torque production, where the rotor saliency of synRM produces mechanical vibrations because of the presence of torque ripples.
\end{abstract}

Keywords: finite-elements, induction motor, syncronous reluctance motor, torque, flux lines.

\section{Introduction}

Induction motor and SynRM are used in many industrial applications. The induction motor offers high effeciency, power density, and still by far the commonly used motors, due to the fact that they are fed directly to the electric network. On the other hand the necessity of SynRM's to a converter circuit to drive the motor, limit their general use and make the drive application too expensive. Nowadays they still adequates for variable speed applications.

Synchronous reluctance motors are being imployed in different applications and traction uses [1], [2], they have a number of advantages, among them the suppression of rotor losses and a simple structure rotor without magnets or cages make them more robust than that of induction motor. The operation of each machine is based on the interaction between the stator magnetic field and the rotor, so both stator and rotor's machine must be taken in concideration when designing machines [3], [4], [5].

In this paper, a comparative study between induction motor and synchronous reluctance motor is proposed. The finite-elements method, is used to an accurate evaluation of magnetic field distribution in motors, any perturbation in this field would indicate a fault presence [6], taking different simulations of electrical motors help researchers to evaluate the performance and the efficiency of each machine, at the same time we can see the influence of several machine faults using electromagnetic simulation which is performed in the time domain under two-dimensional or three-dimensional models.

\section{Description of Machines}

In the present work, a four-pole squirrel cage IM was initially chosen for the purpose of study, the stator is identical for both machines, using a three-phase half coiled winding type, where the stator winding resistance is $3.17 \Omega$ phase and the inductance is $3.23 \mathrm{mH} /$ phase. 


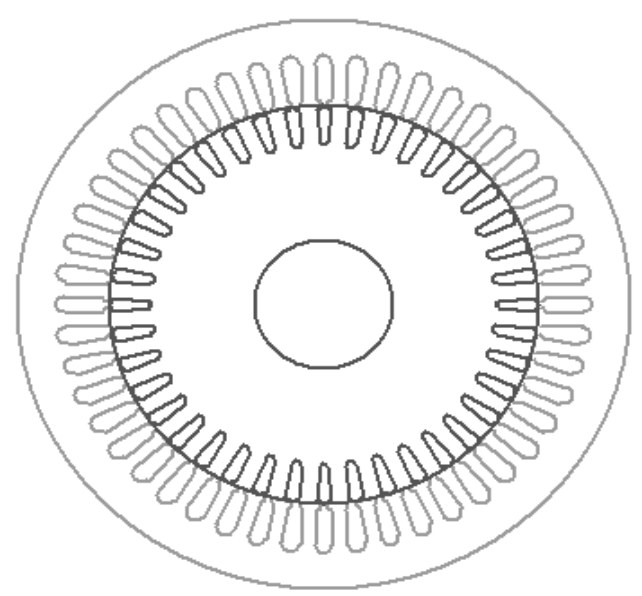

Fig. 1: stator-rotor cross-section of IM.

The cross-section of the stator and the rotor is shown in fig.1, where the other characteristics are in the following tables:

TABLE I: Machine Characteristics

\begin{tabular}{ll}
\hline \hline Name & Value \\
\hline Frequency & $50 \mathrm{~Hz}$ \\
Number of poles & 4 poles \\
Reference speed & $700 \mathrm{rpm}$ \\
Stacking factor & 0.92 \\
\hline \hline
\end{tabular}

TABLE II: Stator Characteristics

\begin{tabular}{ll}
\hline \hline Name & Value \\
\hline Outer diameter & $210 \mathrm{~mm}$ \\
Inner diameter & $148 \mathrm{~mm}$ \\
Length & $250 \mathrm{~mm}$ \\
Number of slots & 48 \\
\hline \hline
\end{tabular}

TABLE III: Rotor Characteristics

\begin{tabular}{ll}
\hline \hline Name & Value \\
\hline Outer diameter & $147.3 \mathrm{~mm}$ \\
Inner diameter & $48 \mathrm{~mm}$ \\
Length & $250 \mathrm{~mm}$ \\
Number of slots & 40 \\
\hline \hline
\end{tabular}

The rotor of synRM has the same characteristics except the number of slots wich is changed to 24 slots, by cutting 4 parts symmetrically, obtaning 4 poles with 6 bars in each pole (fig. 3), these bars are connected to each other. The rotor speed of IM is $1446.1 \mathrm{rpm}$, where the rotor speed of synRM is $1500 \mathrm{rpm}$.

\section{The Electromagnetic Torque}

\subsection{IM Torque}

Torque of a three phase induction motor is proportional to flux per stator pole and rotor current:

$$
T_{I M}=\frac{3}{2} * \frac{p}{2}\left(\phi_{d s} * i_{q s}-\phi_{q s} * i_{d s}\right)
$$

With:

$$
\left\{\begin{array}{c}
\phi_{d s}=L_{d s} * i_{d s}+M * i_{d r} \\
\phi_{q s}=L_{q s} * i_{q s}+M * i_{q r}
\end{array}\right.
$$

and:

$$
M=\frac{3}{2} M_{s r}
$$

Where: $\phi_{\mathrm{ds}}, \phi_{\mathrm{qs}}$ are the $\mathrm{d}$ and $\mathrm{q}$ axis stator flux linkages, $\mathrm{L}_{\mathrm{ds}}, \mathrm{L}_{\mathrm{qs}}$ are the $\mathrm{d}$ and $\mathrm{q}$ axis inductances, $\mathrm{i}_{\mathrm{ds}}, \mathrm{i}_{\mathrm{qs}}$ are the $\mathrm{d}$ and $\mathrm{q}$ axis stator currents, $\mathrm{M}_{\mathrm{sr}}$ is the stator rotor mutual, $\mathrm{p}$ is the number of poles.

Then,

$$
T_{I M}=\frac{3}{2} * \frac{p}{2} * M\left(i_{d r} * i_{q s}-i_{q r} * i_{d s}\right)
$$

\subsection{SynRM torque:}

The electromagnetic torque produced by synRM is identical to that of a synchronous motor, that expressed in equation (4) using d-q axis theory [7]:

$$
T_{R S M}=\frac{3}{2} * \frac{p}{2}\left(\phi_{d s} * i_{q s}-\phi_{q s} * i_{d s}\right)
$$


With:

$$
\left\{\begin{array}{l}
\phi_{d s}=L_{d s} * i_{d s} \\
\phi_{q s}=L_{q s} * i_{q s}
\end{array}\right.
$$

Finally we obtain:

$$
T_{R S M}=\frac{3}{2} * \frac{p}{2}\left(L_{d s}-L_{q s}\right) i_{d s} * i_{q s}
$$

\section{Finite Elements Results}

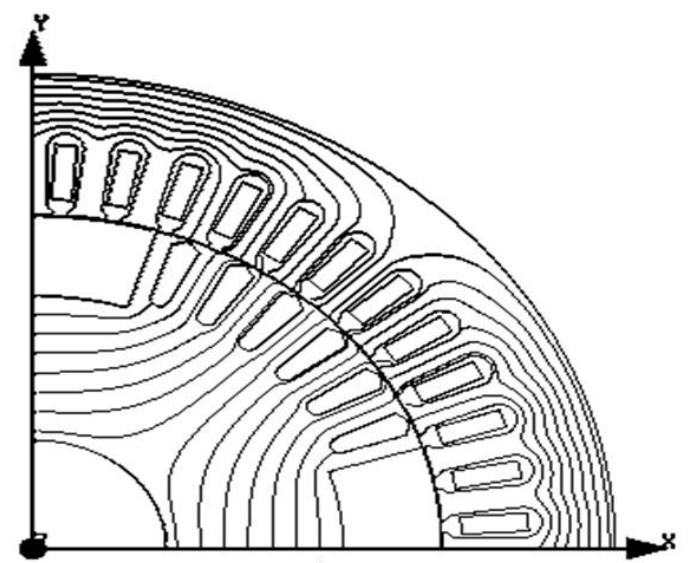

(a)

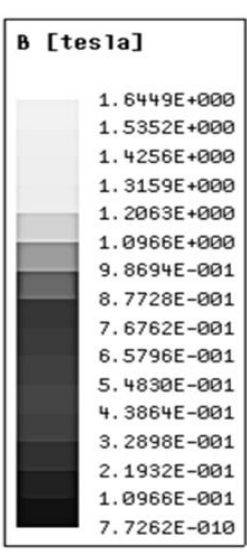

$7262 \mathrm{E}-010$

Fig. 2: a) Flux lines, b) Flux density of IM

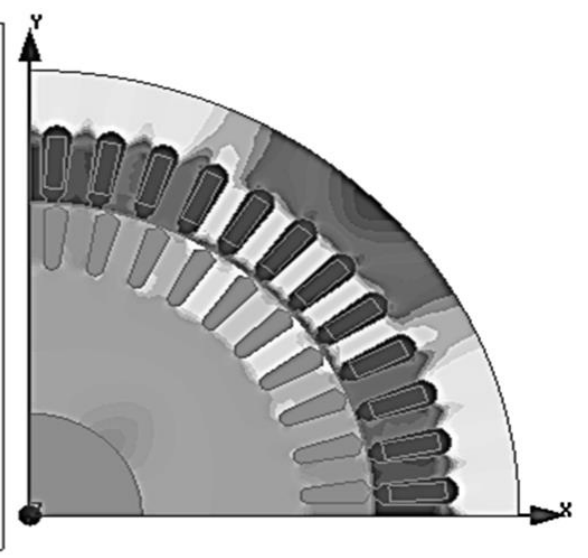

(b)

After modifications, a new configuration is shown in fig. 3 , where the rotor pole arc is equal to $54^{\circ}$.

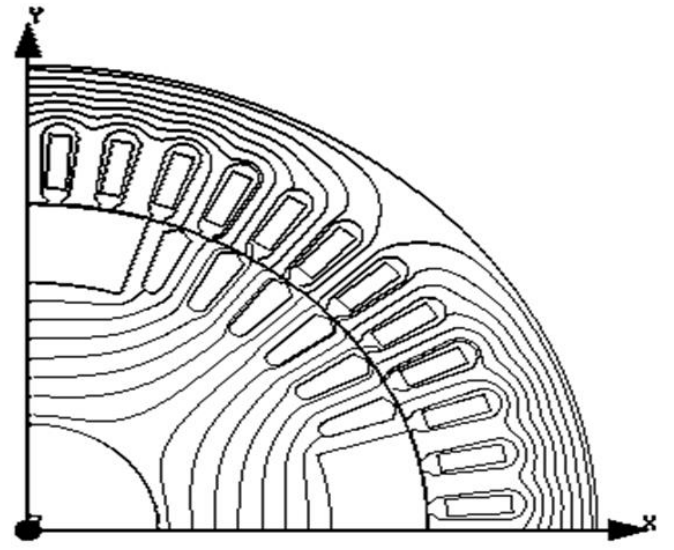

(a)

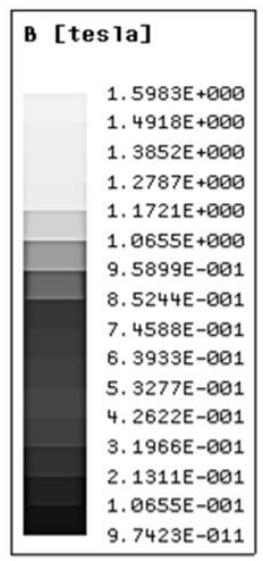

Fig. 3: a) Flux lines, b) Flux density of RSM

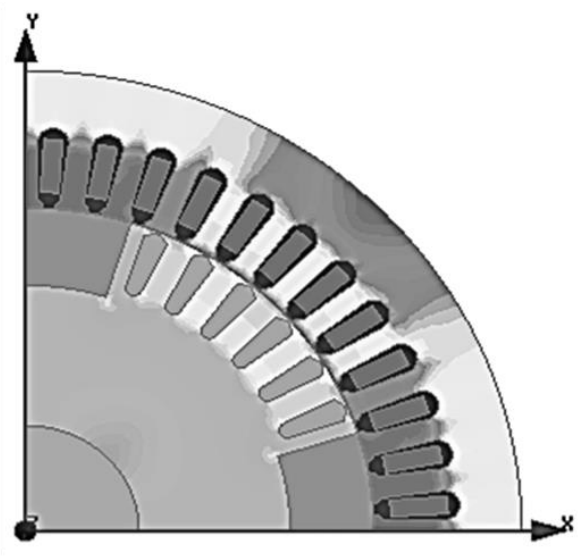

(b)

The magnetostatic analysis of synRM and IM, was performed on the quarter portion of both machines under no-load condition, it shows the same distribution of flux lines, they are symmetrically distributed over the pole arc as shown in figs 2 and 3, however the flux density in IM is more intense than that of synRM because of the number of bars constituting the squirrel cage. 


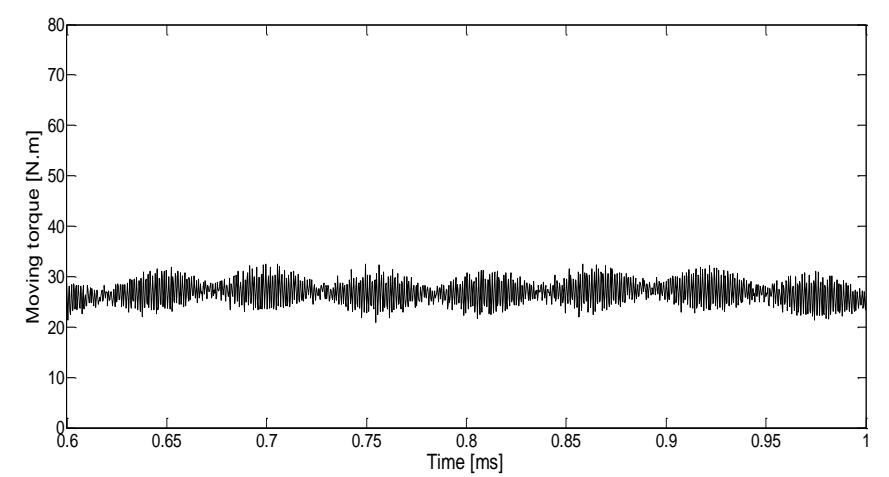

a)

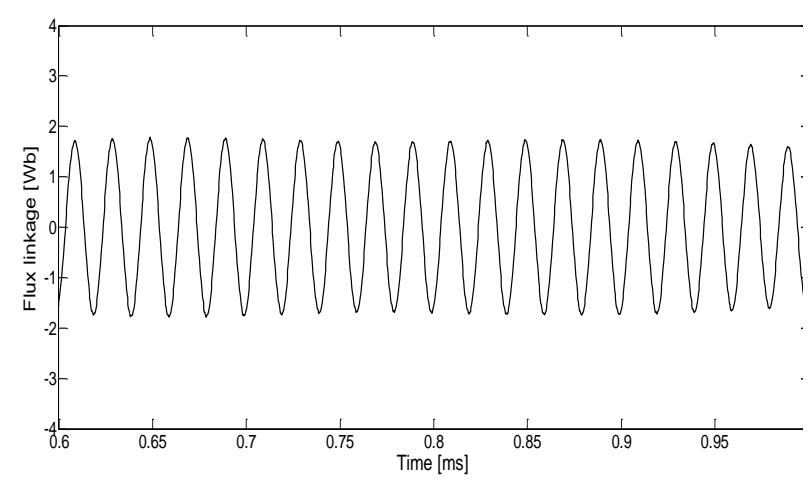

b)

Fig. 4: a) Torque, b) Flux linkage of IM

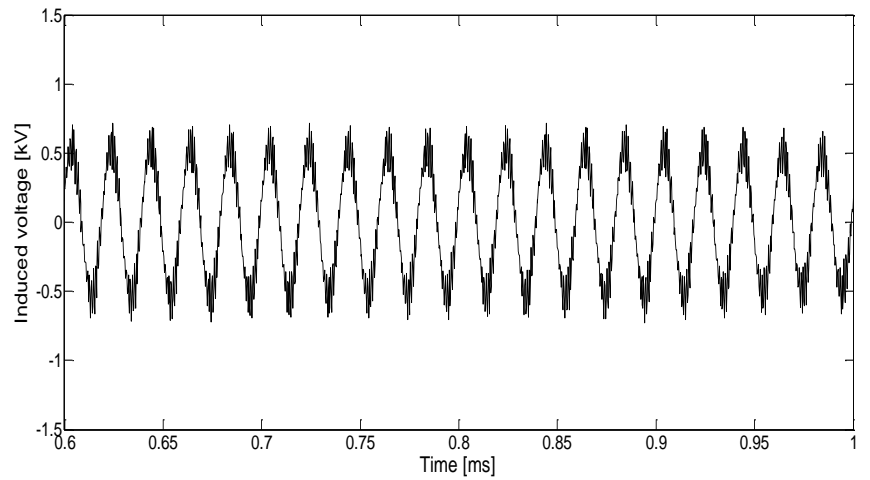

a)

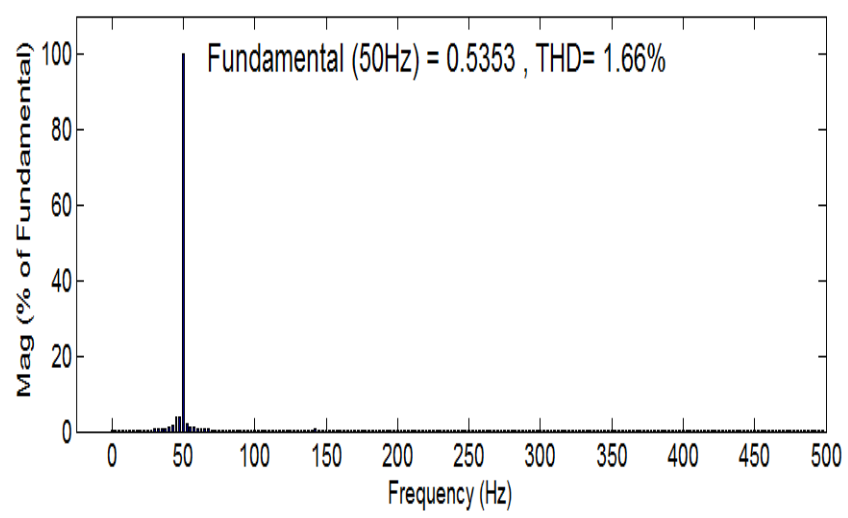

b)

Fig. 5: a) Induced voltage, b) FFT induced voltage of IM

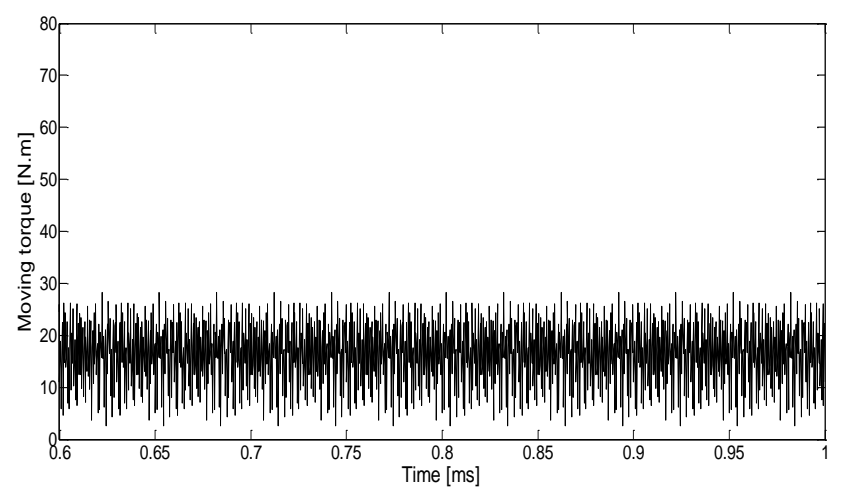

a)

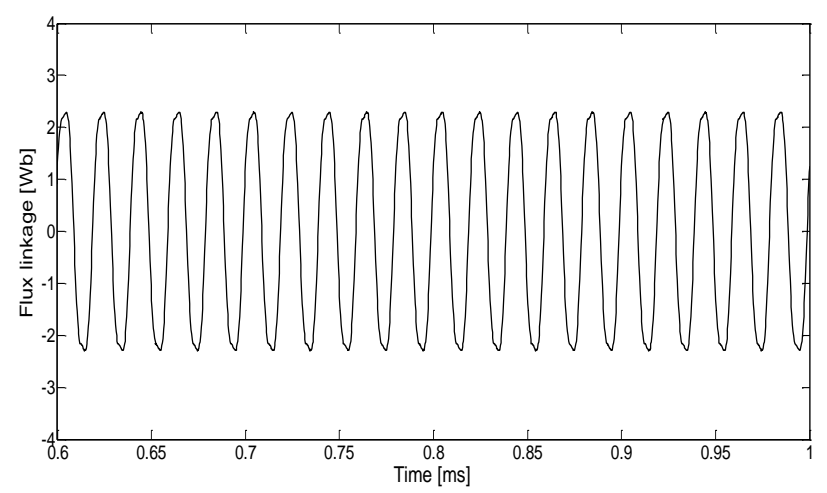

b)

Fig. 6: a) Torque, b) Flux linkage of synRM 


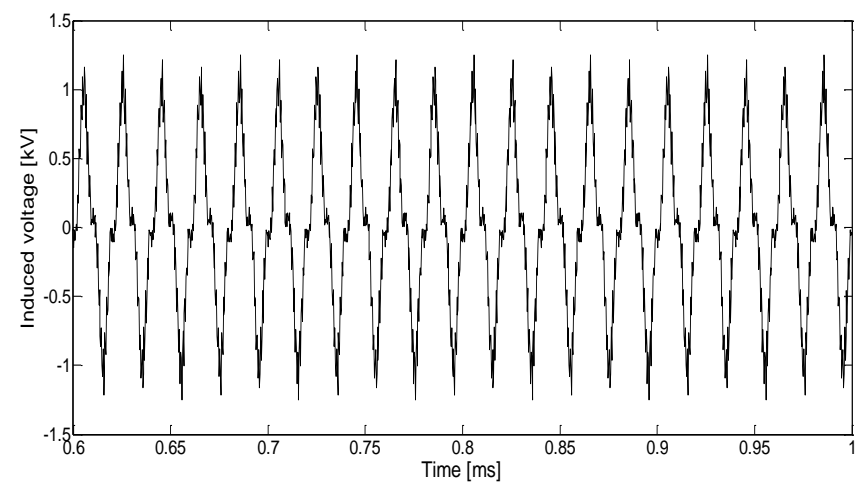

a)

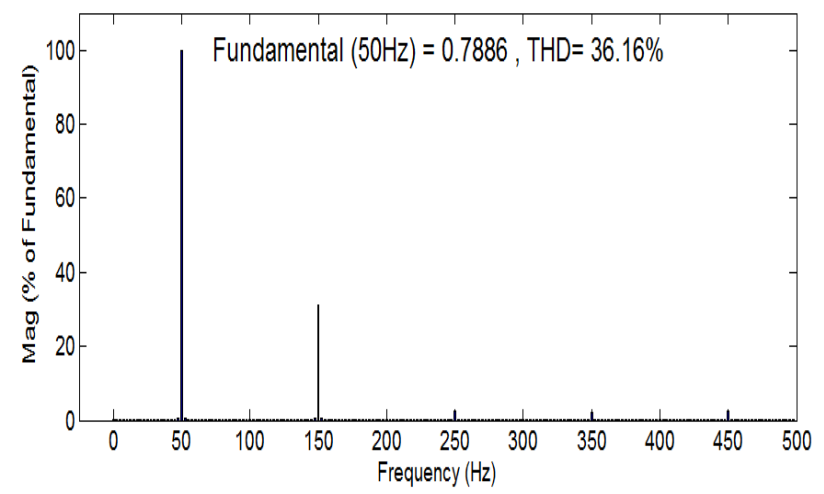

b)

Fig. 7: a) Induced voltage, b) FFT induced voltage of synRM

Both of machines have been simulated under no-load condition with $0.0003 \mathrm{~s}$ as a step time, figs. 4 and 5 show the results of IM, where figs. 6 and 7 illustrate the simulated synRM results, comparing the moving torque, the flux linkage and the induced voltage spectrum with its FFT analysis.

The main difference between synRM and IM is that the electromagnetic torque is low in synRM for the same current in both machines, automatically the induced voltage of synRM increase for the same requirements, on the other hand, the ripples of electromagnetic torque also increase because of the presence of rotor's salience which affects the wave form of the induced voltage obtaining a very high THD corresponds to the appearance of the third harmonic (fig. 7).

\section{Conclusion}

For many years the Induction Motors (IM) have successfully supplied variable demands, and they have become in undeniable leaders in the field, where actually synRMs have a rugged construction, it makes them less heavy compared to induction machines, the structure of designing the rotor of synRM helps to obtain good performances by maximizing the saliency ratio where the machine can produce the maximum of torque, but the major drawback of synRMs, the poor power factor, in this days the power factor is considerably improved using other design modifications, such as multiple flux barrier and axially laminated rotor [8], [9], [10].

In our numerical study, the 2-D model of both machines is applied under healthy conditions, the synRM with salient rotor creates ripples in the electromagnetic torque, that has a direct influence on induced voltage and increase its THD, this variation of torque causes an acoustic noise especially when the motor turn at low speed.

\section{References}

[1] K. M. Rahman, B. Fahimi, G. Suresh, A. V. Rajarathnam, M. Ehsani, "Advantages of Switched Reluctance Motor Applications to EV and HEV: Design and Control Issues", Texas A\&M University, IEEE 1998.

[2] Kyohei Kiyota, Akira Chiba, "Design of Switched Reluctance Motor Competitive to 60-kW IPMSM in ThirdGeneration Hybrid Electric Vehicle", IEEE Transactions on Industry Applications, vol. 48, no. 6, november/december 2012.

https://doi.org/10.1109/TIA.2012.2227091

[3] Arthur V. Radun, "Design Considerations for the Switched Reluctance Motor", IEEE Transactions on Industry Applications, vol. 31, no. 5, September/october 1995. https://doi.org/10.1109/28.464522

[4] Prabhakar Neti, Subhasis Nandi, “ Performance analysis of a Reluctance Synchronous Motor Under Ubnormal Operating Condition”, IEEE, niagara Fallf, May 2004. 
[5] Jin Woo Lee, Hong Seok Kim, Byung Il Kwon, Byung Taek Kim," New Rotor Shape Design for Minimum Torque Ripple of SRM Using FEM", IEEE Transactions on Magnetics, vol. 40, no. 2, march 2004. https://doi.org/10.1109/TMAG.2004.824803

[6] Mohamed El Hachemi Benbouzid, "A Review of Induction Motors Signature Analysis as a Medium for Faults Detection", IEEE Transactions on Industrial Electronics, vol. 47, no. 5, october 2000.

[7] Thomas A. Lipo, "Synchronous Reluctance Machines-A Viable Alternative for AC Drives?", Article in Electric Machines and Power Systems · November 1991.

[8] S. M. de Pancorbo, G. Ugalde, J. Poza, A. Egea, "Comparative Study between Induction Motor and Synchronous Reluctance Motor for Electrical Railway Traction Applications", university of Mondragon, faculty of Engineering, Arrasate-Mondragon, 2015.

[9] Takayoshi Matsuo, Tomas A.Lipo, "Rotor Design Optimization of Synchronous Reluctance Machine", IEEE Transactions on Energy Conversion, Vol 9, June 1994.

https://doi.org/10.1109/60.300136

[10]Aldo Boglietti, Andrea Cavagnino, Michele Pastorelli, David Staton, Alfredo Vagati, " Thermal Analysis of Induction and Synchronous Reluctance Motors ", IEEE Transactions on Industry Applications, vol. 42, may/june 2006.

https://doi.org/10.1109/TIA.2006.873668 